\title{
Stress and Sleep Disorder
}

\author{
Kuem Sun $\mathrm{Han}^{1}$, Lin $\mathrm{Kim}^{2}$ and Insop Shim ${ }^{3 *}$ \\ ${ }^{1}$ College of Nursing, Korea University, Seoul 136-705, ${ }^{2}$ College of Medicine, Korea University, Seoul 136-705, \\ ${ }^{3}$ College of Oriental Medicine, Kyung Hee University, Seoul 130-701, Korea
}

The purpose of this study was to review potential, physiological, hormonal and neuronal mechanisms that may mediate the sleep changes. This paper investigates the literatures regarding the activity of the hypothalamic-pituitary-adrenal (HPA) axis, one of the main neuroendocrine stress systems during sleep in order to identify relations between stress and sleep disorder and the treatment of stress-induced insomnia. Sleep and wakefulness are regulated by the aminergic, cholinergic brainstem and hypothalamic systems. Activation of the HPA and/or the sympathetic nervous systems results in wakefulness and these hormones including corticotropinreleasing hormone $(\mathrm{CRH})$, adrenocorticotropic hormone (ACTH), cortisol or corticosterone, noradrenaline, and adrenaline, are associated with attention and arousal. Stress-related insomnia leads to a vicious circle by activating the HPA system. An awareness of the close interaction between sleep and stress systems is emerging and the hypothalamus is now recognized as a key center for sleep regulation, with hypothalamic neurontransmitter systems providing the framework for therapeutic advances. An updated understanding of these systems may allow researchers to elucidate neural mechanisms of sleep disorder and to develop effective intervention for sleep disorder.

Key words: stress, sleep disorders, psychological stress response

\section{INTRODUCTION}

Stress is a complex condition with emotional, cognitive, and biological factors. Excessive stress causes long- and short-term disability in the various human systems, and activates the defense system of the central nervous system. The stress responses differ depending on the type of stress and the individual's physiological responses. These latter responses consist of neuro-endocrine and behavioral responses, and include the changes in the activity and immune function of the hypothalamo-pituitary-adrenal (HPA) axis.

Sleep is an important component of human homeostasis. Sleep disorders are closely associated with significant medical,

Received November 16, 2012, Accepted December 10, 2012

* To whom correspondence should be addressed.

TEL: 82-2-961-0698, FAX: 82-2-957-0157

e-mail: ishim@khu.ac.kr psychological and social disturbances. Chronic sleep restriction is an increasing problem in many countries. Since the body's stress systems play a critical role in adapting to a continuously changing and challenging environment, it is an important question whether these systems are affected by sleep loss. The human body mobilizes defensive processes in an adaptive effort to maintain homeostasis. If these defenses fail, insomnia may occur. Short-term insomnia is caused by a change in routine such as psychiatric illness, disability, and stress [1].

In the beginning of sleep, the activity of HPA axis is suppressed continually. In the latter part of sleep, the HPA secretory activity increases so it is close to the maximum circadian rhythm immediately after waking up, and the prominent activity of the HPA axis and sympathetic nervous system influences the overall amount of rapid eye movement (REM) sleep [2]. Therefore, the rise of adrenocorticotrophic hormone (ACTH) in the morning is the decisive control factor regulating the end of sleep [3]. The 
fact that the beginning and end of sleep involve HPA axis activity and the close temporal relationship between the axis and sleep provides a clue to estimate the effects of the stress on sleep.

The immune system is also influential in the relationship between stress and sleep. The most important link between the immune system and sleep is established by the cytokines which act as signaling molecules of the immune system such as interleukin-1 beta (IL-1 $\beta$ ), tumor necrosis factor (TNF), and interferon. IL-1 $\beta$, TNF, and interferon are known to participate in the regulation of sleep [4]. If IL-1 $\beta$ or TNF are injected, non-REM (NREM) sleep will increase. But, in the absence of these substances, sleep is interrupted. IL-1 $\beta$ is also involved with the immune regulating feedback chain, which activates the HPA axis, and may be one pathway involved in the relationship between stress and sleep [5].

Typically, stress-related insomnia is transient and persists for only a few days. But, in the clinic setting the real problem is chronic insomnia, which is also called physiological insomnia. The stress-diathesis theory of the onset of chronic insomnia posits the involvement of a series of steps configured by the predisposing, precipitating, and perpetuating factors. A greater understanding is needed about the progress of insomnia caused by stress, particularly physiological insomnia.

In this study, the factors involved in sleep and alertness, their mechanisms of regulation, and the regulatory influences of the activation of HPA axis on stress-related physiological responses and changes in immune function on regulating sleep and alertness mechanisms were examined. As well, the mechanisms by which transient insomnia due to stress becomes chronically stabilized were investigated.

\section{NEURONAL SYSTEMS AND CHEMICALS IN SLEEP AND WAKING}

\section{The arousal system of the brain stem}

The brain stem reticular formation has two dorsal pathways: a pathway towards the thalamus and a pathway towards the basal forebrain. These pathways activate the cerebral cortex [6]. Glutamate is the most common excitatory neurotransmitter in the brain [7] and major function of the reticular formation neurons is to activate the sensory-motor, autonomic neuronal, and cerebral cortex by the secretion of glutamate[8]. The pedunculopontine tegmental nuclei and the laterodorsal tegmental nuclei (PPT/LDT) which release acetylcholine play an important role on wakefulness by projecting through the thalamus, hypothalamus, and the basal forebrain [9]. Cholinergic neurons reciprocally enervate with the thalamus, the locus coeruleus (LC), and the raphe nuclei (DRN) [10]. Experimentally, acetylcholine in the cerebrum prompts was reported to be increased during alertness and, more abundantly,
REM sleep [11]. Noradrenergic neurons of the LC spread out widely to the overall brain, and they activate alertness, followed by NREM, with activity being lowest during REM sleep [12]. When the LC is stimulated, the activity of the cerebral cortex (i.e., EEG) is increased [13], and the changes in the LC activity are increased by new stimulation and various stressors. Stress may activate the LC activity by secretion of corticosteroid releasing hormone (CRH) in the paraventricular nucleus of the hypothalamus [14]. The nigrostriatal dopaminergic pathway promotes waking in motor activity, and inhibits sleep [15]. But, the mesocortical and mesolimbic dopaminergic neurons in the ventral tegmental area (VTA) of the midbrain affect the cerebral cortex and the limbic systems, regulating alertness. Serotonergic neurons of the DRN are activated during waking state, and are inhibited in REM sleep [16]. Serotonergic neurons are involved in the generating of slow wave, but are not activated during sleep [17]. The collective data to data are consistent with the view that the serotonergic neurons are responsible for some of the activating systems, but seem to reduce the cortex activation by exerting an inhibitory influence on other neurons responsible for alertness [7]. Serotonin 5-HT1A receptors are expressed in the gamma-aminobutyric acid (GABA) ergic neurons of the basal forebrain [18]. GABAergic neurons are hyperpolarized by secreting 5-HT in the DRN. Therefore, if GABAergic neurons are inhibited by 5-HT1A receptor agonist, then wakefulness can be indirectly caused by increasing acetylcholine in the cortex.

\section{Hypothalamic arousal systems}

When the hypothalamus is stimulated, a series of arousal reactions including the activation of the HPA axis, the cortex, and the autonomic nervous system are elicited [19]. The posterior hypothalamus, which is involved in alertness, uses glutamate as the primary neurotransmitter [20]. The tuberomammillary neurons (TM) located in the posterior hypothalamus are the only histamine neurons in the brain; they receive information from numerous activation-related regions of the brain stem and the ventrolateral preoptic area (VLPO) [21]. Histamine modulates to maintain cortical activity and wakefulness. Orexin, which is also called hypocretin, is secreted by neurons in the lateral and medial hypothalamus [22]. The orexin neurons project to the cerebral cortex, and most of arousal regions including monoaminergic and cholinergic neurons and connect with the preoptic area (POA) and $\mathrm{BF}$.

A lack of orexin causes narcolepsy. Orexin is activated in the alertness condition, and especially plays a role in motor activity. The orexin neurons reciprocally project to VLPO neuron, but there are no orexin receptors in the VLPO [23]. Therefore, the 
orexin neurons reinforce alertness, but do not directly suppress the VLPO, and the asymmetrical relationship seems to contribute to make the flip-flop switch stable, which stops conduction to unwanted sleep. As a result, the activity of the LC, which is inactivated during REM, is predominated by orexin neurons, which led to conclusion that orexin is a target for regulating REM sleep [24].

\section{POA}

The VLPO as a sleep center contains GABAergic/galaninergic neurons, which act as an inhibitory neurotransmitter. POA neurons principally use histamine, and so assume to be involved in alertness and NREM $[25,26]$. VLPO neurons send terminals to the DRN and LC, which have important roles for REM. Conversely, GABAergic neurons in the VLPO are suppressed by noradrenalin and serotonin [27] and $\mathrm{H} 2$ receptors are suppressed by histamine. c-Fos-immunoreactive neurons (Fos-IRNs) in the VLPO and median preoptic nucleus (MnPN) have been closely correlated with existing sleep quantity. In particular, Fos-IRNs were increased during sleep recovery after sleep deprivation [28]. These findings show that the VLPOA is a crucial neural substrate for sleep promotion. Adenosine promotes sleep by exciting the neural activity of the POA [27], while on the other hand it facilitates sleep by suppressing the alertness-activating neurons such as cholinergic neurons [29].

Cytokines including IL1- $\beta$ and TNF influence homeostatic sleep control [30]. TNF- $\alpha$ causes NREM via the POA and the LC. In experiments with mice, the injection of TNF- $\alpha$ in these regions resulted in increased NREM, and the LC suppressed noradrenaline alertness mechanisms. Prostaglandin D2 (PGD2) is another important endogenous sleep factor that also acts in the POA. Growth hormone-releasing hormone (GHRH) also plays an important role in the regulation of NREM [30].

\section{THE PROCESS OF SLEEP REGULATION}

\section{Schema of a typical entrained 24-hour day}

Sleeping involves sufficient periods of wakefulness and decline of core temperature, which are merged to open the "gate" to sleep. The beginning of sleep involves the first circadian vertex of slow wave sleep. The pressure of slow wave sleep decreases with time. Generally, the vertex of circadian REM can be set between the half-cycle of two slow wave sleep pressures. To minimize sleepiness in the early evening and to maintain proper alertness, three factors seem to be critical: low pressure of slow wave sleep, REMminimum pressure of sleep, and peak core temperature. Sleep and alertness are mutually competitive and necessarily exclusive; the development of alertness is the reverse of sleep pressure. In the late evening core temperature begins to decrease, and somnolence related to sustained alertness continuously increases. This cycle is repeated thereafter.

\section{Homeostatic process of sleep}

Slow wave activity is a physiological indicator of NREM sleep homeostasis. Slow wave activity can be considered an indicator of the depth or intensity of sleep. The stimulus reaction decreases depending on the increase of slow wave activity, and this activity is inversely correlated with alertness [31]. In addition, the process of comprehensive slow wave sleep is high in the beginning of sleep but decreases gradually thereafter [32]. Spectral analysis of brainwave activity revealed a change in density of average brainwave between $0.25-2.0 \mathrm{~Hz}$ depending on the process of sleep [33]. A nap late in the afternoon includes increased slow wave sleep than a nap early in the afternoon [34]. Shorter duration of night-time sleep produces increased slow wave activity in a nap the next morning [35]. Concerning the effects of sleep deprivation, recovery sleep includes increased slow wave sleep following the deprivation of partial or full sleep [32]. Especially, the increase of slow wave sleep is markedly enhanced in the first day of recovery sleep, as the extension of alertness period [36].

The immune system is involved with the various stress responses, and homeostasis during sleep and generation of NREM. Levels of TNF and IL1- $\beta$ in the brain change with time courses; a study conducted in a mouse model demonstrated high levels of TNF mRNA and protein in the cortex and hypothalamus when sleep inclination was maximal. In the study, sleep deprivation was linked with an increase in the brain density of cytokine. In addition, upregulation of cytokine and somnolence was also evident in mice challenged with infection. Bacterial cell wall muramyl peptides and viral double strand RNA [37] reinforce cytokine production, similar to compounds including IL $1-\beta$ and TNF. If TNF is injected in the POA of the hypothalamus, it reinforces REM, while injections of TNF soluble receptor at the same site spur a spontaneous decrease in sleep. Injections of IL1- $\beta$ receptors at the same site suppress alertness-activating neurons and stimulate sleep-activating neurons [30]. TNF or IL1- $\beta$ reinforces sleep in these areas as well as in other regions of the brain, if TNF or IL1- $\beta$ is injected directly into the cerebral cortex; slow wave sleep is increased in the injected half of the brain sphere. Similarly, injection of TNF soluble receptor or IL1- $\beta$ soluble receptor suppressed the increases of slow wave sleep after sleep deprivation in the injected half-sphere [38].

Cytokines, especially TNF and IL1- $\beta$, act on the sleep control circuit and are involved with sleep-related morbidity. IL1- $\beta$, IL2, 
IL6, IL8, IL15, IL18, TNF, fibroblast growth factor, and nerve growth factor are some of the cytokines that have been shown to reinforce sleep. But, IL4, IL10, IL13, and insulin-like growth factor as among the cytokines that suppress sleep. These sleep regulatory substances (SRS) are responsible for some regulatory mechanisms that maintain the ark of the cycle of long-lasting sleep/alertness, and so have been linked to sleep homeostatic mechanisms [30]. After sleep deprivation, the production of interferon (IFN), TNF, and IL1- $\beta$ was increased [37]. Sleep apnea can accompany sleep deprivation and hypoxia, and involves an increase of TNF [37]. IL1- $\beta$ and TNF activate nuclear factor-kappa $B(N F \kappa B)$ and c-Fos (AP-1), transcription factors, and a myriad of short halflife, small molecules such as activated nitric oxide adenosine, and prostaglandins [39]. Adenosine causes NFKB nuclear translocation in the basal forebrain. $\mathrm{NF \kappa B}$ is activated by sleep deprivation [40].

Summarizing the molecular connection related to homeostasis of sleep, SRS including TNF, IL1- $\beta$, and NGF are generated or secreted by neuron throughout the waking period, in a process that can be affected by stress. SRS production/secretion can be subject to positive or negative feedback regulation from transcription factors such as NFKB, cytokines, and hormones. Cytokine production and activity includes transcription and detoxification, and their direct actions on sleep were mediated by nitric oxide and adenosine, whose short half-lives enable ready and swift response [5].

\section{Circadian process of sleep}

The circadian cycle of physical function continues without outside temporal clues from the beginning, and it is natural and that the cycle is precisely 24 hours [35]. People naturally feel sleepy at night, due to the fatigue resulting from daily life rather than the screening of the internal clock, so sleep can be delayed by appropriate stimuli. As a result, the fact that determination of sleep time is changed by the circadian mechanisms in daily life can be overlooked. Control of circadian rhythm by REM is not related to sleep time, but the peak REM tendency is coincident with the peak nadir of body temperature in the early morning. Somnolence is regulated by homeostatic and behavioral results, and circadian rhythm. The tendency of sleep is consistently high when the rhythm of human body temperature is disrupted; the result is a need for sleep in early afternoon (i.e., nap, siesta). This distribution reflects the phase of the circadian cycle, which is determined endogenously.

The suprachiasmatic nucleus (SCN) is the "master clock" of the brain. SCN neurons are activated in a 24-hour transcription and detoxification cycle. Animal experiments have demonstrated that SCN removal abrogates the circadian rhythm of behavioral and physiological processes, which can prevent sleep [41]. Under normal circumstances, melatonin in the SCN will be reset every day by being secreted by the light entering through the eyes in the morning and from the pineal at night [42]. The light is detected by series of ganglion cells equipped with the predisposing factor melanopsin, which is delivered to the SCN. Information from SCN neurons is amplified in the near sub-paraventricular zone (SPZ) [43]. The neurons from the DMH deliver the information to neurons responsible for circadian secretion, which regulates hormones such as orexin neuron related to VLPO and alertness as central sleep, body temperature and corticosteroids, and thyrotropin-releasing hormone. Therefore, sleep-wake, activity, feeding, temperature and corticosteroid rhythms are changed equivalent to the DMH variable activity [44].

Core temperature is one of the physiological progresses regulated by the circadian pacemaker. Sleep begins when the core temperature falls from its peak. Sleep ends following the nadir of core temperature. In addition to the circadian rhythm of core temperature, one of the important substances involved in the regulation of sleep-wakefulness rhythm is melatonin. Dim light melatonin onset (DLMO) begins 2-3 hours before the usual start time of sleep [45]. The DLMO is relatively less affected by exogenous factors, so it is recognized as reliable marker to measure the circadian rhythm of humans. In addition to melatonin, other substances involved in regulating the sleep-wakefulness circadian rhythm are corticosteroids. Endogenous rhythm influences the circadian rhythm of HPA secretion through the multi-synaptic SCN-adrenal pathway [46]. Cortisol secretion is very rhythmic, and is maintained at a low level during the day and at the beginning of night, but the secretion increases from the latter part of the night towards morning. The nadir of cortisol appears within 2 hours after the start of sleep. In other words, sleep begins when cortisol is lowest and finishes when cortisol is highest. Physical or physiological stress changes cortisol secretion by activating the HPA axis.

\section{THEORETICAL MODELS OF INSOMNIA}

\section{Stress as a precipitating factor}

Post-traumatic stress disorder (PTSD) is an extreme case of stress-related insomnia, which occurs after traumatic experiences. According to Hefez et al. [47], individuals who have experienced extremely traumatic events shows more recollection of a dream with low sleep efficiency. Cartwright and Wood [48] reported that sleep can be easily disrupted in people undergoing divorce, with decreased delta sleep. Kageyama et al. [49] asserted the relevance of the subjective quality of reporting between career stress and 
poor sleep, and Hall et al. [50] opined that stress-related thinking is connected with insomnia. Verlander et al. [51] reported that an emotional reaction is the best predictor for explaining the factors such as depth and quality of sleep among three stress factors: burden events, personality mediators, and emotion reactions. Paulsen and Shaver [52] reported that the negative life events have indirect effects only, but do affect objective sleep. Cernovsky [53] demonstrated that the major stress and sleep obstacles are not closely correlated, and that the negative life-cycle is somewhat connected with sleep obstacles among the various sleep factors. Reynolds et al. [54] reported that REM is increased in the brain waves of the people who have experienced bereavement, but it does not affect the rate of sleep efficiency, REM latency, and delta sleep.

In the 1980s, the interest in minor stress (i.e., "hassles") was heightened by considering coping mechanism of individuals about stress or personality of characteristics separate from previous trends in major stress events such as death and divorce, which lead to significant changes in life. The daily worry and frustration that are a routine occurrence have been proposed as harmful for individual's health [55]. Thus, minor stress is a more important factor than the major stress, can have bigger effects on the disease and psychological and physical symptoms, and can be a better predictor. Hick and Garcia [56] reported that the increasing stress lessens the length of sleep. The influence of stress as the trigger or influence of insomnia has been inconsistent. However, according to the Diagnostic and Statistical Manual of Mental Disorders, 4th edition (DSM-IV), "Most of the insomnia occurs with acute for psychological, social and medical stress"; in one study, 78\% insomnia patients reported a link between such stresses and insomnia [57].

In several prospective studies, the main predictors of insomnia were depression, health problems, physical inability, and mental and social state [58]. In addition, while stress is acknowledged as an important risk factor of insomnia, Morin et al. [59] opined that its' significance differs between the insomnia patients and affected individuals concerning an individual's reaction to the of frequency of stress.

\section{Stress and related sleep physiology}

Stress activates the sympatho-adreno-medullary (SAM) and HPA systems, influencing cardiovascular, catecholamine, cortisol, ACTH, and CRH hyperactivity [60]. The stress system interacts by endocrines, the gastrointestinal and immune systems, and positive/negative feedback pathways [61]. Excessive secretion of cortisol negatively affects neural structures such as the hippocampus, resulting in memory deficits [62] and, especially, negatively influences sleep by affecting the activity of the SAM and HPA systems [63]. The immune system is also affected by stress; the autonomic nervous system activates genes involved in production of immune substances such as cytokines [64].

Increased activity of the autonomic nervous system [65] and cortisol causes alertness. Increased ACT influences awakening. Therefore, awakening from sleep after stress can be related to the early increase of ACTH [66]. It has been shown that the injection of ACTH increases sleep latency, decreases slow wave sleep, and fragments sleep [67]. For example, the receptor activity of mineral corticosteroid increases NREM, and the receptor activity of glucocorticosteroid increases alertness and REM [66]. In experiments where mice were immobilized or subjected to social stimulation, decreased slow wave sleep and REM were documented, and their increase during recovery sleep was revealed [68]. Acute and chronic stress decreases slow wave sleep and REM in mice exposed to stress, but a normal sleep pattern was re-established upon recovery. In an acute stress situation, $\mathrm{CRH}$ (an ACTH secretion hormone) mediates the stress reaction in the central nervous system [69]. CRH acting as a neurotransmitter in the LC activates noradrenaline neurons in the LC. But, under chronic stress, distal corticosteroids increase and sleep is disrupted. Therefore, in chronic stress, the reaction of slow wave sleep and REM is not significant.

The immune system is important in the relationship between stress and sleep. Acute or chronic stress in humans and animals considerably affects sleep through the immune system. Acute stress mainly activates the immune system related to natural killer (NK) cells mediated by catecholamine [70]. Meanwhile, chronic stress down-regulates the immune system by decreasing $B$ and $T$ cells and reducing NK cell activity [71]. This occurs in depression and PTSD [71]. IL1- $\beta$ is also involved in an immune regulated feedback that activates the HPA axis. This is involved in the relationship between stress and sleep. Blood IL-1 $\beta$ levels change depending on the cycle of sleep-alertness, and blood TNF is related to the slow wave activity of brainwaves. Also, there is a strong correlation between the degree of the loss of sleep continuity and NK cell function obstacles [72].

Inversely, insomnia causes physiological responses like those in stress situations. Sleep increases growth hormone and testosterone [73], and reduces metabolism and blood flow, to fight against stress [74]. In a state of insomnia, cortisol, heart rate, central temperature, and oxygen consumption are increased [2], as are glucose tolerance [75] and cytokines [76]. Sleep deprivation increases ghrelin and decreases leptin, which exacerbates appetite [77]. Evidence to date indicates (bit has not confirmed) a close connection between stress and sleep. Stress causes pyscho- 
physiological responses and activates the HPA system, which are incompatible with normal sleep. Also, insomnia causes a vicious circle of stress-insomnia by further activating the HPA system. Especially, chronic stress can cause continuous hippocampusrelated memory system fatigue by up-regulating the HPA system. The long-term impacts of chronic stress remain unclear.

\section{Physiological model}

Patients with insomnia, despite lacking night sleep and daytime fatigue, are at a higher state of alertness than those who have appropriate sleep, which has also been demonstrated by the fact that patients with insomnia have longer sleep latency than a control group consisting of ordinary people who sleep upon an execution of latency repeat inspection. This suggests that insomnia is an over-alertness obstacle ranging for 24 hours, and not one limited only to nighttime [78]. As another piece of evidence of over-alertness, patients with insomnia have an increased metabolic rate for 24 hours, their sympathetic nervous system is relatively exacerbated [78], and their adrenal cortex hormone and cortisol density are markedly increased compared to ordinary people [2]. HPA axis activity-related cytokine hypersecretion or daily cycle fluctuation can explain insomnia-related fatigue and poor sleep. Also, patients with insomnia have an increased relative rate of beta-power in brainwaves while awake during the hypnagogic period in which the delta power declines, which suggests the alertness of the central nervous system [79]. The nervous system circuit interacting through brain imaging techniques plays an important role for the neuronal physiology of insomnia [80], in which general alertness system (upturn reticula formation and hypothalamus), the system that regulates emotions (hippocampu, tonsil, anterior cingulate cortex) and cognitive system (prefrontal lobe), are involved.

\section{Behavioral model}

According to a behavioral model proposed by Spielman et al. [81], insomnia is presumed to be caused acutely by both constitutional and causal factors. Acute insomnia is gradually and chronically strengthened and stabilized by a nonadaptive reaction strategy. In other words, if an insomnia episode begins, patients choose various nonadaptive strategies intended to produce more sleep (e.g., spending excessive time in bed and staying awake in bed for a long time). These behaviors reduce sleep efficiency, which results in conditioned alertness during usual sleep and the occurrence of chronic insomnia.

\section{Cognitive model}

A cognitive model first proposed by Morin [82] notes that concern and reflection by early stress disrupts sleep and causes an acute episode of insomnia. The individual's reactions to this transient sleep trouble (i.e., behaviors, beliefs, attitudes, and interpretations) contribute to sustaining or deteriorating the subsequent insomnia. Once sleep disturbance begins, concern and reflection changes from life stress to sleep itself, and with daytime symptoms in the absence of sufficient sleep. This negative cognitive activity is further strengthened if one feels threatened related to sleep or perceives a lack of sleep [83]. Moreover, monitoring day-time symptoms due to sleep and lack of sleep causes autonomic neuronal alertness and emotional distress, which causes selective attention to threatening clues associated with sleep to sustain insomnia [84]. Such a chain reaction causes a state of over-alertness, which conflicts with a state of relaxation needed for inducing sleep. Excessive concern with sleep and fear for not having sleep generates bad sleep habits such as taking a nap or staying in bed for a long time, which collapses the sleepalertness cycle and homeostasis of sleep. In a nutshell, regardless of the causes of insomnia in an early phase, bad sleep habits and non-functional recognition of sleep are almost always involved in perpetuating or deteriorating sleep obstacles over time [85].

\section{Neurocognitive model}

Patients with insomnia tend to overestimate their sleep latency, while tending to underestimate their overall sleep time (i.e., they say it takes a long time to fall asleep and that they do not sleep in). Polysomnogram data indicate wakefulness even if sleep begins, which prompts awakening. Also, for patients with insomnia, use of benzodiazepine-based sleeping pills does not normalize sleep, although patients report more benefits attributed to the medication than can be explained by objective variables with improved sleep [86]. Cognitive neural perspective focusing on cortex alertness measured by brainwave activity allows patients with insomnia to explain diagnostically the paradox in the patients [86]. The consistency of the behavioral model is that the neuronal cognitive model concerns the view that acute insomnia is stirred by living stress, while continuous insomnia is caused by maladjusted countermeasures, and that chronic insomnia results from conditioned alertness. The difference of the neuronal cognitive model on chronic insomnia focuses on cortical arousal, a form of conditioned alertness [86]. According to the neuronal cognitive model, hypnagogue or high frequency brainwave activity at that time is a primary feature of chronic insomnia, and conditioned alertness in this form prompts various sensory and cognitive phenomena that do not occur during quality sleep.

The theoretical model of insomnia is a stress-constitution model, which argues that pre-onset predisposing factors, precipitating 
factors like stress, and subsequent perpetuating factors causes the expression of insomnia. In other words, people with insomnia have a characteristic of the predisposing factors of insomnia, the precipitating factors including cause an actual artwork, such acute insomnia is strengthened by nonadaptive reaction strategy to become chronically stabilized. Physiological, cognitive, and awakening of intellectual mind, maladjusted behavior, circadian rhythm, and sleep homeostatic obstacles can be the perpetuating factors that perpetuate transient insomnia caused by stress.

\section{MANAGING INSOMNIA THROUGH DAILY LIFE STRESS MA- NAGEMENT}

Insomnia caused by various stress factors can be prevented and managed by managing everyday life habits. The management of day-to-day lifestyle can be divided into mental and physical aspects based on the comprehensive model of stress [87]. As the management of mental aspect, since the perception and evaluation of the factor rather than the event itself significantly affect stress, one should make efforts to change his/her cognitive evaluation to a more positive one and to reduce everyday life stress. This can be accomplished by maintaining the balance between work and rest by releasing stress at the moment to deal with the stress, expressing concerns or problems with the expression of emotional tension, maintaining an inner balance with reality by accepting what cannot be changed and accepting what is wrong, trying to plan and record a daily routine and form a habit of setting priorities, And seeking solutions by simplifying the pertinent issue when facing a complicated and difficult problem [88].

The management of day-to-day lifestyle in physical aspect includes regular and balanced meals, Balanced physical activity by regular moderate motion about for $30 \mathrm{~min}$., 3-4 times a week, (e.g., stretching, jogging, biking or hiking), and induced body rest and relaxation, such as controlled respiration and muscle tension methods.

Most of all, goal-setting, continuing to make constant efforts toward the goals, accepting the fact that no one is perfect, and doing one's best can help overcome insomnia caused by stress.

\section{CONCLUSIONS}

Excessive stress is detrimental on many levels to humans, and it activates the defense system of the central nervous system. Stress-related physiological responses differ depending on each individual cognitive form, and these physiological responses cause the neuro-endocrine responses and behavioral responses. Sleep is an essential biological process for humans. Many anatomical structures and biochemical substances are involved in the regulating mechanisms including the HPA axis, which is activated by the factors including stress and immune function. The regulation of sleep is configured with the circadian process that determines the beginning and ending of sleep, and the homeostatic process that maintains the depth and the amount of sleep. In the early stage of sleep, the activity of HPA axis is suppressed and ongoing, while in the latter part of sleep HPA secretion activity increases. The increased HPA axis and activity of the sympathetic nervous system influences rapid eye movement (REM) sleep. Components of immune system including IL-1 $\beta$ are involved in the homeostatic regulating mechanisms of sleep. In addition, IL- $1 \beta$ participates in the immune regulating feedback chain that activates the HPA axis. Stress-related insomnia leads to a vicious circle by activating the HPA system. Chronic insomnia, which is termed physiological insomnia, is a clinical problem. The stressdiathesis theory concerning the onset of chronic insomnia posits the involvement of a series of factors consisting of predisposing, precipitating, and perpetuating factors. Stress-induced insomnia that becomes chronically stabilized is connected to the treatment, so that an understanding of the perpetuating factor is essential.

\section{ACKNOWLEDGEMENTS}

This study was supported by a KBSI grant (T31901) to SH.

\section{REFERENCES}

1. Partinen M (1994) Sleep disorders and stress. J Psychosom Res 38 Suppl 1:89-91.

2. Vgontzas AN, Bixler EO, Lin HM, Prolo P, Mastorakos G, Vela-Bueno A, Kales A, Chrousos GP (2001) Chronic insomnia is associated with nyctohemeral activation of the hypothalamic-pituitary-adrenal axis: clinical implications. J Clin Endocrinol Metab 86:3787-3794.

3. Weibel L, Follenius M, Spiegel K, Ehrhart J, Brandenberger G (1995) Comparative effect of night and daytime sleep on the 24-hour cortisol secretory profile. Sleep 18:549-556.

4. Takahashi S, Kapás L, Fang J, Krueger JM (1999) Somnogenic relationships between tumor necrosis factor and interleukin-1. Am J Physiol 276:R1132-R1140.

5. Krueger JM, Rector DM, Churchill L (2007) Sleep and cytokines. Sleep Med Clin 2:161-169.

6. Steriade M, Oakson G, Ropert N (1982) Firing rates and patterns of midbrain reticular neurons during steady and transitional states of the sleep-waking cycle. Exp Brain Res 46:37-51. 
7. Jones BE (2005) From waking to sleeping: neuronal and chemical substrates. Trends Pharmacol Sci 26:578-586.

8. Stenberg D (2007) Neuroanatomy and neurochemistry of sleep. Cell Mol Life Sci 64:1187-1204.

9. McCormick DA (1989) Cholinergic and noradrenergic modulation of thalamocortical processing. Trends Neurosci 12:215-221.

10. Ford B, Holmes CJ, Mainville L, Jones BE (1995) GABAergic neurons in the rat pontomesencephalic tegmentum: codistribution with cholinergic and other tegmental neurons projecting to the posterior lateral hypothalamus. J Comp Neurol 363:177-196.

11. Vazquez J, Baghdoyan HA (2001) Basal forebrain acetylcholine release during REM sleep is significantly greater than during waking. Am J Physiol Regul Integr Comp Physiol 280: R598-R601.

12. Chu N, Bloom FE (1973) Norepinephrine-containing neurons: changes in spontaneous discharge patterns during sleeping and waking. Science 179:908-910.

13. Berridge CW, Foote SL (1991) Effects of locus coeruleus activation on electroencephalographic activity in neocortex and hippocampus. J Neurosci 11:3135-3145.

14. Valentino RJ, Foote SL (1988) Corticotropin-releasing hormone increases tonic but not sensory-evoked activity of noradrenergic locus coeruleus neurons in unanesthetized rats. J Neurosci 8:1016-1025.

15. Trulson ME (1985) Activity of dopamine-containing substantia nigra neurons in freely moving cats. Neurosci Biobehav Rev 9:283-297.

16. McGinty DJ, Harper RM (1976) Dorsal raphe neurons: depression of firing during sleep in cats. Brain Res 101:569575.

17. Trulson ME, Jacobs BL (1979) Raphe unit activity in freely moving cats: correlation with level of behavioral arousal. Brain Res 163:135-150.

18. Lüttgen M, Ogren SO, Meister B (2005) 5-HT1A receptor mRNA and immunoreactivity in the rat medial septum/ diagonal band of Broca-relationships to GABAergic and cholinergic neurons. J Chem Neuroanat 29:93-111.

19. Bailey TW, Dimicco JA (2001) Chemical stimulation of the dorsomedial hypothalamus elevates plasma ACTH in conscious rats. Am J Physiol Regul Integr Comp Physiol 280:R8R15.

20. Ziegler DR, Cullinan WE, Herman JP (2002) Distribution of vesicular glutamate transporter mRNA in rat hypothalamus. J Comp Neurol 448:217-229.

21. Panula P, Pirvola U, Auvinen S, Airaksinen MS (1989)
Histamine-immunoreactive nerve fibers in the rat brain. Neuroscience 28:585-610.

22. Sakurai T, Amemiya A, Ishii M, Matsuzaki I, Chemelli RM, Tanaka H, Williams SC, Richardson JA, Kozlowski GP, Wilson S, Arch JR, Buckingham RE, Haynes AC, Carr SA, Annan RS, McNulty DE, Liu WS, Terrett JA, Elshourbagy NA, Bergsma DJ, Yanagisawa M (1998) Orexins and orexin receptors: a family of hypothalamic neuropeptides and $\mathrm{G}$ protein-coupled receptors that regulate feeding behavior. Cell 92:573-585.

23. Marcus JN, Aschkenasi CJ, Lee CE, Chemelli RM, Saper CB, Yanagisawa M, Elmquist JK (2001) Differential expression of orexin receptors 1 and 2 in the rat brain. J Comp Neurol 435:6-25.

24. Bourgin P, Huitrón-Résendiz S, Spier AD, Fabre V, Morte B, Criado JR, Sutcliffe JG, Henriksen SJ, de Lecea L (2000) Hypocretin-1 modulates rapid eye movement sleep through activation of locus coeruleus neurons. J Neurosci 20:77607765.

25. Lu J, Bjorkum AA, Xu M, Gaus SE, Shiromani PJ, Saper CB (2002) Selective activation of the extended ventrolateral preoptic nucleus during rapid eye movement sleep. J Neurosci 22:4568-4576.

26. Ko EM, Estabrooke IV, McCarthy M, Scammell TE (2003) Wake-related activity of tuberomammillary neurons in rats. Brain Res 992:220-226.

27. Gallopin T, Luppi PH, Cauli B, Urade Y, Rossier J, Hayaishi O, Lambolez B, Fort P (2005) The endogenous somnogen adenosine excites a subset of sleep-promoting neurons via $\mathrm{A} 2 \mathrm{~A}$ receptors in the ventrolateral preoptic nucleus. Neuroscience 134:1377-1390.

28. Sherin JE, Shiromani PJ, McCarley RW, Saper CB (1996) Activation of ventrolateral preoptic neurons during sleep. Science 271:216-219.

29. Basheer R, Strecker RE, Thakkar MM, McCarley RW (2004) Adenosine and sleep-wake regulation. Prog Neurobiol 73:379-396.

30. Obal F Jr, Krueger JM (2003) Biochemical regulation of nonrapid-eye-movement sleep. Front Biosci 8:d520-d550.

31. Franken P, Dijk DJ, Tobler I, Borbély AA (1991) Sleep deprivation in rats: effects on EEG power spectra, vigilance states, and cortical temperature. Am J Physiol 261:R198-R208.

32. Webb WB, Agnew HW Jr (1971) Stage 4 sleep: influence of time course variables. Science 174:1354-1356.

33. Borbély AA, Baumann F, Brandeis D, Strauch I, Lehmann D (1981) Sleep deprivation: effect on sleep stages and EEG power density in man. Electroencephalogr Clin Neurophysiol 
51:483-495.

34. Beersma DG, Daan S, Dijk DJ (1987) Sleep intensity and timing: a model for their circadian control. Lect Math Life Sci 19:39-62.

35. Akerstedt T, Gillberg M (1986) Sleep duration and the power spectral density of the EEG. Electroencephalogr Clin Neurophysiol 64:119-122.

36. Dijk DJ, Brunner DP, Borbély AA (1991) EEG power density during recovery sleep in the morning. Electroencephalogr Clin Neurophysiol 78:203-214.

37. Majde JA, Krueger JM (2005) Links between the innate immune system and sleep. J Allergy Clin Immunol 116:11881198.

38. Yoshida H, Peterfi Z, García-García F, Kirkpatrick R, Yasuda T, Krueger JM (2004) State-specific asymmetries in EEG slow wave activity induced by local application of TNFa. Brain Res 1009:129-136.

39. Luk WP, Zhang Y, White TD, Lue FA, Wu C, Jiang CG, Zhang L, Moldofsky H (1999) Adenosine: a mediator of interleukin1beta-induced hippocampal synaptic inhibition. J Neurosci 19:4238-4244

40. Brandt JA, Churchill L, Rehman A, Ellis G, Mémet S, Israël A, Krueger JM (2004) Sleep deprivation increases the activation of nuclear factor kappa B in lateral hypothalamic cells. Brain Res 1004:91-97.

41. Moore RY, Eichler VB (1972) Loss of a circadian adrenal corticosterone rhythm following suprachiasmatic lesions in the rat. Brain Res 42:201-206.

42. Cassone VM, Chesworth MJ, Armstrong SM (1986) Entrainment of rat circadian rhythms by daily injection of melatonin depends upon the hypothalamic suprachiasmatic nuclei. Physiol Behav 36:1111-1121.

43. Deurveilher S, Semba K (2005) Indirect projections from the suprachiasmatic nucleus to major arousal-promoting cell groups in rat: implications for the circadian control of behavioural state. Neuroscience 130:165-183.

44. Saper CB, Lu J, Chou TC, Gooley J (2005) The hypothalamic integrator for circadian rhythms. Trends Neurosci 28:152157.

45. Lewy AJ, Cutler NL, Sack RL (1999) The endogenous melatonin profile as a marker for circadian phase position. J Biol Rhythms 14:227-236.

46. Buijs RM, Wortel J, Van Heerikhuize JJ, Feenstra MG, Ter Horst GJ, Romijn HJ, Kalsbeek A (1999) Anatomical and functional demonstration of a multisynaptic suprachiasmatic nucleus adrenal (cortex) pathway. Eur J Neurosci 11:15351544 .
47. Hefez A, Metz L, Lavie P (1987) Long-term effects of extreme situational stress on sleep and dreaming. Am J Psychiatry 144:344-347.

48. Cartwright RD, Wood E (1991) Adjustment disorders of sleep: the sleep effects of a major stressful event and its resolution. Psychiatry Res 39:199-209.

49. Kageyama T, Nishikido N, Kobayashi T, Kurokawa Y, Kaneko T, Kabuto M (1998) Self-reported sleep quality, job stress, and daytime autonomic activities assessed in terms of short-term heart rate variability among male white-collar workers. Ind Health 36:263-272.

50. Hall M, Buysse DJ, Nowell PD, Nofzinger EA, Houck P, Reynolds CF 3rd, Kupfer DJ (2000) Symptoms of stress and depression as correlates of sleep in primary insomnia. Psychosom Med 62:227-230.

51. Verlander LA, Benedict JO, Hanson DP (1999) Stress and sleep patterns of college students. Percept Mot Skills 88:893898.

52. Paulsen VM, Shaver JL (1991) Stress, support, psychological states and sleep. Soc Sci Med 32:1237-1243.

53. Cernovsky ZZ (1984) Life stress measures and reported frequency of sleep disorders. Percept Mot Skills 58:39-49.

54. Reynolds CF 3rd, Hoch CC, Buysse DJ, Houck PR, Schlernitzauer M, Pasternak RE, Frank E, Mazumdar S, Kupfer DJ (1993) Sleep after spousal bereavement: a study of recovery from stress. Biol Psychiatry 34:791-797.

55. Weinberger M, Hiner SL, Tierney WM (1987) In support of hassles as a measure of stress in predicting health outcomes. J Behav Med 10:19-31.

56. Hicks RA, Garcia ER (1987) Level of stress and sleep duration. Percept Mot Skills 64:44-46.

57. Bastien CH, Vallières A, Morin CM (2004) Precipitating factors of insomnia. Behav Sleep Med 2:50-62.

58. Linton SJ (2004) Does work stress predict insomnia? A prospective study. Br J Health Psychol 9:127-136.

59. Morin CM, Rodrigue S, Ivers H (2003) Role of stress, arousal, and coping skills in primary insomnia. Psychosom Med 65:259-267.

60. Dunn AJ, Berridge CW (1990) Physiological and behavioral responses to corticotropin-releasing factor administration: is CRF a mediator of anxiety or stress responses? Brain Res Brain Res Rev 15:71-100.

61. Chrousos GP, Gold PW (1992) The concepts of stress and stress system disorders. Overview of physical and behavioral homeostasis. JAMA 267:1244-1252.

62. McEwen BS, Sapolsky RM (1995) Stress and cognitive function. Curr Opin Neurobiol 5:205-216. 
63. Rock JP, Oldfield EH, Schulte HM, Gold PW, Kornblith PL, Loriaux L, Chrousos GP (1984) Corticotropin releasing factor administered into the ventricular CSF stimulates the pituitary-adrenal axis. Brain Res 323:365-368.

64. Bierhaus A, Wolf J, Andrassy M, Rohleder N, Humpert PM, Petrov D, Ferstl R, von Eynatten M, Wendt T, Rudofsky G, Joswig M, Morcos M, Schwaninger M, McEwen B, Kirschbaum C, Nawroth PP (2003) A mechanism converting psychosocial stress into mononuclear cell activation. Proc Natl Acad Sci U S A 100:1920-1925.

65. Kato T, Montplaisir JY, Lavigne GJ (2004) Experimentally induced arousals during sleep: a cross-modality matching paradigm. J Sleep Res 13:229-238.

66. Born J, Fehm HL (1998) Hypothalamus-pituitary-adrenal activity during human sleep: a coordinating role for the limbic hippocampal system. Exp Clin Endocrinol Diabetes 106:153-163.

67. Steiger A, Guldner J, Knisatschek H, Rothe B, Lauer C, Holsboer F (1991) Effects of an ACTH/MSH(4-9) analog (HOE 427 ) on the sleep EEG and nocturnal hormonal secretion in humans. Peptides 12:1007-1010.

68. Meerlo P, Pragt BJ, Daan S (1997) Social stress induces high intensity sleep in rats. Neurosci Lett 225:41-44.

69. Marinesco S, Bonnet C, Cespuglio R (1999) Influence of stress duration on the sleep rebound induced by immobilization in the rat: a possible role for corticosterone. Neuroscience 92:921-933.

70. Benschop RJ, Godaert GL, Geenen R, Brosschot JF, De Smet MB, Olff M, Heijnen CJ, Ballieux RE (1995) Relationships between cardiovascular and immunological changes in an experimental stress model. Psychol Med 25:323-327.

71. Kiecolt-Glaser JK, Glaser R (1995) Psychoneuroimmunology and health consequences: data and shared mechanisms. Psychosom Med 57:269-274.

72. Irwin M, Smith TL, Gillin JC (1992) Electroencephalographic sleep and natural killer activity in depressed patients and control subjects. Psychosom Med 54:10-21.

73. Axelsson J, Ingre M, Akerstedt T, Holmbäck U (2005) Effects of acutely displaced sleep on testosterone. J Clin Endocrinol Metab 90:4530-4535.

74. Braun AR, Balkin TJ, Wesenten NJ, Carson RE, Varga M, Baldwin P, Selbie S, Belenky G, Herscovitch P (1997) Regional cerebral blood flow throughout the sleep-wake cycle. An H2(15)O PET study. Brain 120:1173-1197.

75. Renko AK, Hiltunen L, Laakso M, Rajala U, KeinänenKiukaanniemi S (2005) The relationship of glucose tolerance to sleep disorders and daytime sleepiness. Diabetes Res Clin
Pract 67:84-91.

76. Vgontzas AN, Zoumakis E, Lin HM, Bixler EO, Trakada G, Chrousos GP (2004) Marked decrease in sleepiness in patients with sleep apnea by etanercept, a tumor necrosis factor-alpha antagonist. J Clin Endocrinol Metab 89:44094413.

77. Spiegel K, Tasali E, Penev P, Van Cauter E (2004) Brief communication: sleep curtailment in healthy young men is associated with decreased leptin levels, elevated ghrelin levels, and increased hunger and appetite. Ann Intern Med 141:846850.

78. Bonnet MH, Arand DL (1995) 24-Hour metabolic rate in insomniacs and matched normal sleepers. Sleep 18:581-588.

79. Lamarche CH, Ogilvie RD (1997) Electrophysiological changes during the sleep onset period of psychophysiological insomniacs, psychiatric insomniacs, and normal sleepers. Sleep 20:724-733.

80. Nofzinger EA, Buysse DJ, Germain A, Price JC, Miewald JM, Kupfer DJ (2004) Functional neuroimaging evidence for hyperarousal in insomnia. Am J Psychiatry 161:2126-2128.

81. Spielman AJ, Caruso LS, Glovinsky PB (1987) A behavioral perspective on insomnia treatment. Psychiatr Clin North Am 10:541-553.

82. Morin CM (1993) A cognitive-behavioral conceptualization of insomnia. In: Insomnia: psychological assessment and management (Morin CM, ed), pp 46-60. Guilford Press, New York.

83. Harvey AG (2002) A cognitive model of insomnia. Behav Res Ther 40:869-893.

84. Espie CA (2002) Insomnia: conceptual issues in the development, persistence, and treatment of sleep disorder in adults. Annu Rev Psychol 53:215-243.

85. Edinger JD, Fins AI, Glenn DM, Sullivan RJ Jr, Bastian LA, Marsh GR, Dailey D, Hope TV, Young M, Shaw E, Vasilas D (2000) Insomnia and the eye of the beholder: are there clinical markers of objective sleep disturbances among adults with and without insomnia complaints? J Consult Clin Psychol 68:586-593.

86. Perlis ML, Giles DE, Mendelson WB, Bootzin RR, Wyatt JK (1997) Psychophysiological insomnia: the behavioural model and a neurocognitive perspective. J Sleep Res 6:179-188.

87. Han KS (2007) Stress of the mid-life stage. Korean J Stress Res 15:263-270.

88. Seaward BL (2009) Managing stress: principles and strategies for health and well-being, 6th ed. Jones and Bartlett Publishers, Sudbury, MA. 